\title{
STATISTICAL DETECTION OF DENSITY DEPENDENCE FROM A SERIES OF SEQUENTIAL CENSUSES ${ }^{1}$
}

\author{
NORMAN A. SLADE \\ Museum of Natural History and Department of Systematics and Ecology, \\ University of Kansas, Lawrence, Kansas 66045 USA
}

\begin{abstract}
The use of simple linear regression to estimate slopes of plots of $N(t+1)$ against $N(t)$ as a test of density dependence has been criticized because such data violate the assumption of negligible measurement error in the independent variable and because they represent a time series rather than independent pairs of points. Of the several alternatives which have been suggested, ordinary and standard major axes and the coefficient of first-order autoregression behave in accordance with the logic of detecting density dependence in such plots. The power of the test of the slopes' being equal to 1 depends on the magnitude of density-dependent and independent (random) influences and on the type of error, measurement or environmental. However, slopes of major axes appear to be unbiased estimators of the true slopes, when sequential population estimates include values sufficiently displaced from equilibrium conditions. If data follow a purely autoregressive process, density dependence can be detected without such displacement.
\end{abstract}

Key words: Autoregression; density dependence; density independence; error regression; Morris plots; major axes; regression; von Neuman's ratio.

\section{INTRODUCTION}

For many years one of the principal controversies in population ecology has centered on the relative importance of negatively density-dependent (DD; per capita rate of increase decreases as population increases) and density-independent (DI) influences on populations. Recently, this question has taken on more importance with the interest in the different selective pressures that occur in DD or DI dominated environments (MacArthur and Wilson 1967, Pianka 1970, 1972, Wallace 1975, and others).

Assessment of DD from a series of population estimates, $N(t)$, has been hindered by the lack of a suitable statistical technique. Several different techniques have been proposed and criticized (Eberhardt 1970, Itô 1972, and Varley et al. 1974). The specific method considered in this paper is that of Morris (1959) applied to successive estimates of population size from comparable points in a time series, i.e., the same developmental stage for organisms with nonoverlapping generations or the same place in an annual cycle for organisms with overlapping generations. Morris's (1959) suggestion that $\log N(t+1)$ be regressed against $\log N(t)$ with an expected slope of one if DD factors are not important has been criticized by Eberhardt (1970), Maelzer (1970), St. Amant (1970), Luck (1971), Kuno (1971), Itô (1972), Benson (1973), Pielou (1974), and Dempster (1975).

The logic underlying Morris's technique is simple. If populations increase or decrease independent of population density, their change through time should follow the simple equation for exponential growth, expressed in linear form for a single time interval as

${ }^{1}$ Manuscript received 29 July 1976; accepted 3 June 1977.

$$
X(t+1)=r+\beta X(t),
$$

where $X(t)=\ln N(t)$ and $\beta=1$.

In the absence of variation in $r$, a plot of $X(t+1)$ against $X(t)$ should, and indeed does, produce a straight line with slope of 1 . If DD factors are important in determining a population's trajectory through time, the ratio $N(t+1) / N(t)$ and the difference $X(t+1)-X(t)$ should decrease as $N(t)$ and $X(t)$ increase. With DD, a plot of $X(t+1)$ against $X(t)$ should show a slope, $\beta$, less than 1 . Introduction of random variation increases the scatter of the plot of $X(t+1)$ versus $X(t)$, but ideally should not affect the slope of the line fitted to those points other than to widen the confidence interval about the estimated slope.

The foregoing logic seems correct yet Morris's method has been shown to become unreliable as random variation increases by Eberhardt (1970), St. Amant (1970), Maelzer (1970), Kuno (1971), and Itô (1972). Kuno (1971), Itô (1972), Benson (1973), and Bulmer (1975) contended this was a result of choosing $b_{\mathrm{R}}$, the simple linear regression coefficient, to estimate $\beta$, the true coefficient of $X(t)$ in equation 1. Kuno (1971) and Itô (1972) argued that sampling error in measuring population size causes the regression slope to underestimate the true slope as observed in the simulation studies of St. Amant (1970) and Maelzer (1970). Benson (1973) agreed that the regression slope was a biased estimator of $\beta$ but pointed out that it was not always negatively biased. Bulmer (1975) approached the problem as a time series analysis and dismissed the simple regression coefficient as a biased estimator of the coefficient of first order autoregression.

Because of the bias of the simple regression coefficient as an estimator of $\beta$, Varley and Gradwell (1963) 
recommended regressing $X(t+1)$ against $X(t)$ and vice vers $a$, rejecting the hypothesis of $\beta$ being 1 , only when both calculated regression slopes are significantly different from one on the same side of unity, i.e., both the slope of $X(t+1)$ against $X(t)$ and the inverse of the slope of $X(t)$ against $X(t+1)$ should be $<1$. Dempster (1975) cited much of the literature on this problem and concluded that Varley and Gradwell's (1963) technique was the best test available. Itô $(1972: 361)$ criticized the regression of $X(t)$ against $X(t+1)$ as being nonsense in a predictive sense but as Benson (1973) stated, prediction is not the object of regression in this case. As Varley and Gradwell (1963) suggested, the combined confidence intervals around $b_{y \cdot x}$ and $1 / b_{x \cdot y}$ provide the most conservative (widest) confidence intervals for the true slopes of $y$ regressed against $x$ when error can occur in either or both variables (Moran 1971; Ricker 1973). However, with Morris plots as I have defined them, parametric error variances in both variables should be equal and Varley and Gradwell's (1963) technique should prove too conservative.

Deming (1943) presented a method of estimating the slope, $b_{\mathrm{P}}$, of a bivariate relationship with error in both variables when $\lambda$, the ratio of parametric error variances of the dependent and independent variables, is known.

$$
\begin{aligned}
b_{\mathrm{P}}= & \left\{\sum y^{2}-\lambda \sum x^{2}+\left[\left(\lambda \sum x^{2}-\sum y^{2}\right)^{2}\right.\right. \\
& \left.\left.+4 \lambda\left(\sum x y\right)^{2}\right]^{1 / 2}\right\} / 2 \sum x y,
\end{aligned}
$$

where $\sum y^{2}=$ sum of squared deviations from the mean for the dependent variable,

$\sum x^{2}=$ sum of squared deviations for the independent variable,

and $\quad \sum x y=$ sum of products of deviations from the mean.

Jolicoeur and Heusner (1971) used this method to estimate allometric growth parameters and Ricker (1973, 1975) and Jolicoeur (1975) discussed its general applications. By assuming equal errors in $X(t)$ and $X(t+1)$, $\lambda=1$ and the formula reduces to that for the slope of the major or principal axis of a bivariate scatter plot (Pearson 1901, formula in Ricker 1975 or Sokal and Rohlf 1969), which Slade (1976) suggested could be used to test for DD.

Ricker $(1973,1975)$ criticized the slope of the major axis because it varies with the unit of measurement and Deming's (1943) more general method as requiring $\lambda$ which is frequently difficult to determine. Citing Teissier (1948), Ricker proposed that "GM regression" or the major axis of standardized variates (Jolicoeur 1975) be used to measure the slope of trend lines with error in both variables. The slope of the standard major axis, $b_{\mathrm{s}}$, is calculated as

$$
b_{\mathrm{S}}=\left(\sum y^{2} / \sum x^{2}\right)^{1 / 2}
$$

Ricker (1973) also discussed two types of random errors, natural error induced by stochastic variation in the environment, and measurement error, i.e., census errors in Morris's (1959) problem. Jolicoeur (1975:1493) stated that the source of error about the trend line was statistically irrelevant as long as errors from both sources were samples from the same distribution.

Bulmer (1975) proposed using the inverse of Von Neuman's ratio to test for DD and derived a table of critical values for that purpose. He also suggested that $\beta$ be estimated by $b_{\mathrm{A}}$, which he calculated from the coefficient of first order serial correlation, $r_{1}$, as

$$
b_{\mathrm{A}}=r_{1}+\left(1+3 r_{1}\right) / n
$$

where $n$ is the total number of points in the time series. Because actual field data are likely to involve both the problems of serial correlations and of errors of measurement, Bulmer also presented a second method of testing for DD which is more robust to measurement errors.

Of these methods, only those of Ricker (1973) and Jolicoeur (1975) have been compared but they were not discussed with reference to the problem of DD. This paper reports the results of computer simulations designed to compare the results of all of these proposed methods of analysis over a range of models and parameter values.

\section{MeTHODS}

Simulated series of $X(t)$ values were generated by modifying Eq. 1, incorporating random effects representing either natural error, measurement error, or both. Equation I was not used because I believed it to be the most realistic population growth model (May et al. [1974] and Hassell [1975] discuss various properties and compare it to other growth models), but because it was the basis of Morris's (1959) argument and Maelzer (1970) and St. Amant's (1970) criticism. Even if other models prove to be more realistic, their behavior in the neighborhood of equilibrium points, when they exist, may be approximately linear on a log scale.

Three series of simulations were run using three combinations of random error. The first series used the model,

$$
X(t+1)=r+\beta X(t)+\epsilon(t),
$$

where all $\epsilon$ were random normal variables with mean zero and standard deviation 0.577 or 1.155 , and $r, \beta$, and $X(0)$, the initial value of the logarithm of population size, were input parameters. This model simulates population growth with what Ricker (1973) called natural errors because deviation of the actual per capita growth rate, $r+\epsilon(t)$, from the parametric mean value, $r$, is incorporated into $X(t+1)$ and used for calculating $X(t+2)$.

The second model,

$$
X(t+1)=r+\beta[X(t)-\gamma(t-1)]+\gamma(t),
$$


where all $\gamma$ are random normal variables from the same distribution as $\epsilon$ of Eq. 5 and all other terms are as previously defined, simulates population growth with only measurement errors. That is, all $\gamma$ are errors in estimating the population and are removed from the $X(t)$ before calculating $X(t+1)$.

The third model,

$$
X(t+1)=r+\beta[X(t)-\gamma(t-1)]+\gamma(t)+\epsilon(t)
$$

was used to simulate the presence of both types of error. All symbols are as previously defined. For these runs, all $\epsilon$ and $\gamma$ were drawn from the same normal distribution having mean zero and standard deviation 0.408 so that the variance of their sum was equal to the variance of the error terms of Eq. 5 and 6.

The estimators of $\beta, b_{\mathrm{p}}$ and $b_{\mathrm{S}}$, for each of 100 runs of length $n=7,22$, or 122 time units were calculated from Eq. 2 and 3 given in the introduction of this paper, substituting $X(t+1)$ for $Y$ and $X(t)$ for $X$ in the equations. Regression slopes, $b_{\mathrm{R}}$ and $1 / b_{x \cdot y}$, for Varley and Gradwell's (1963) test were calculated using the standard formula (Sokal and Rohlf 1969:417) with $X(t+1)$ as the dependent variable. The estimator of the first serial correlation coefficient, for calculating $b_{\mathrm{A}}$ in Eq. 4 was

$r_{1}=\sum_{t=0}^{n-1}\{[X(t+1)-\bar{X}][X(t)-\bar{X}]\} / \sum_{t=0}^{n}[X(t)-\bar{X}]^{2}$,

where $\bar{X}$ is the mean of $X(t)$ over all $t$ from 0 to $n$.

The statistical tests used for slopes being $<+1$ were the standard one-tailed $t$-test $\left(t ._{.10, n-2}\right.$ for $\left.\alpha=0.05\right)$ for simple linear regressions (Sokal and Rohlf 1969: 424 ), and the failure of the upper bound of $90 \%$ confidence limits to exceed +1 for the major and standard major axes. Confidence limits for the major axis were determined using the formula of Box 15.5 in Sokal and Rohlf (1969) with a chi-square value of 2.706. Confidence limits for the standard major axis were determined by the formula of Jolicoeur and Mosimann (1968) as given in Ricker (1975), using $F_{.10,1, n-2 \text {. }}$

To test Bulmer's (1975) analysis, the quantity

$$
R=\sum_{t=0}^{n}[X(t)-\bar{X}]^{2} / \sum_{t=0}^{n-1}[X(t+1)-X(t)]^{2}
$$

was compared to critical values of $0.4696,1.0186$, and 4.6786 calculated from Bulmer's (1975) Table 1 and Eq. 5. Sample sizes, $n$, were 8,23 , and 123 because $X(0)$ was included as a point in the time series. The quantity

$R^{*}=\sum_{t=0}^{n-2}[X(t+2)-X(t+1)][X(t)-\bar{X}] / \sum_{t=0}^{n}[X(t)-\bar{X}]^{2}$,

which provides a test of DD more robust to measurement error according to Bulmer (1975), was compared to critical values of $-0.7378,-0.3833$, and -0.1025 calculated from his Eq. 9.
For each simulation series, the mean and standard error of the calculated slopes were recorded as well as the number of null hypotheses $(\beta=1)$ rejected. Simulations were initially run on the PDP 11 computer at the Laboratory of Brain Evolution and Behavior, National Institutes of Health Animal Center and gave results similar to those presented here from runs on the Honeywell 635 at the University of Kansas. The entire series of simulations were also run using uniformly distributed errors having the same mean and standard deviations as the normal errors to test the robustness of the various analyses to the assumption of normality used in deriving them.

Even though I have referred to Eqs. 5-7 as population growth models, many of the simulations actually involved a decrease in $X(t)$ through time. This does not affect the general results of the statistical analyses as demonstrated by several simulations involving initial values equally deviant from equilibrium values but in opposite directions. The advantage of using initial values which exceed equilibrium values is that one can start the series far from equilibrium density without using negative values of $X(0)$ which represent fractional densities and produce an inflection point in the population growth curve at $X(t)=0$.

\section{Results AND Discussion}

As an example of the difference between the major axes and regression lines with $\beta=1$, Fig. 1 shows the example of Pielou (1974) as accurately as I could duplicate it from her Fig. 4.3. Because my calculated slopes are not the same as those she gives, the reproduction was not perfect. Nevertheless, when the random variation is small (Fig. 1A) the point to line distances are small and the slopes of the regression line $\left(b_{\mathrm{R}}\right)$ and the major axis $\left(b_{\mathrm{p}}\right)$ are almost equal. As the scatter increases (Fig. 1B), the two estimators diverge $\left(b_{\mathrm{R}}=0.767, b_{\mathrm{P}}=0.939\right)$. The standard major axes were indistinguishable from the major axes in Fig. 1 $\left(b_{\mathrm{s}}=0.967\right.$ and 0.951$)$, whereas the slope estimated from the serial correlation coefficient (not shown) changed from 1.02 to 0.695 . None of the slopes were significantly different from +1 , but the slopes of major axes appear to be least sensitive to random variation.

\section{Autoregressive model}

Density independence.-By using Eq. 5, with $\beta$ equal to 1 , i.e., complete density independence, and $r=0$, the $\log$ of population numbers should follow a random walk about $X(0)$. This is the classic autoregressive model used by Maelzer (1970), St. Amant (1970), and Bulmer (1975). The mean slope of the standard major axis, $\overline{b_{\mathrm{s}}}$, for 100 sequences was nearly one regardless of the number of time periods per sequence or the variance of $\epsilon$ (Table 1$)$. The mean regression slope, $\overline{b_{\mathrm{R}}}$, major axis slope, $\overline{b_{\mathrm{P}}}$, and slope calculated from Eq. $8, \sqrt{b_{\mathrm{A}}}$, increased with the number of points. For $n \geqslant 22, \overline{b_{\mathrm{P}}} \simeq 1$, but $\overline{b_{\mathrm{R}}}$ was only 0.96 with 122 

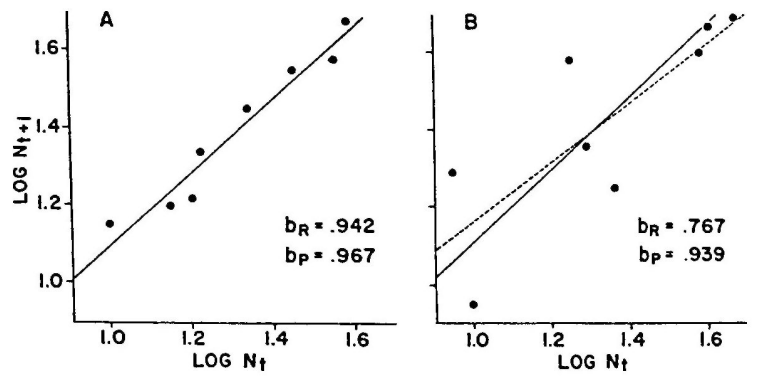

FIG. 1. Regression lines and principal axes for plots of $\log N_{t+1}$ against $\log N_{t}$ (modified from Pielou 1974).

time periods. The negative bias of $\overline{b_{\mathrm{R}}}$ and rejection of many true null hypotheses simply confirmed the conclusions of Maelzer (1970) and St. Amant (1970). The apparent bias of $b_{\mathrm{A}}$ was surprising because Bulmer (1975) devised this statistic to apply specifically to this model, though he did not give mean values of $b_{\mathrm{A}}$ from his simulations. With sequences of length 22 or more, the standard errors of $b_{\mathrm{R}}$ and $b_{\mathrm{A}}$ were $\approx 2 \times$ those of $b_{\mathrm{P}}$ and $b_{\mathrm{s}}$. However, $s_{b_{\mathrm{p}}}$ increased much more rapidly at small sample sizes than did the other standard errors so $b_{\mathrm{P}}$ was the least precise estimate with small samples even though it may be more accurate than $b_{\mathrm{A}}$ or $b_{\mathrm{R}}$. The reliability of the chi-square test for $\beta=1$ using $b_{\mathrm{P}}$ is also affected by sample size. With $\alpha=0.05$, one would expect to reject five true hypotheses in 100 such tests. This obtains for samples $\geqslant 22$, but for $n=7$, more than five true hypotheses were rejected using $b_{\mathrm{p}}$. As expected, Varley and Gradwell's (1963) technique is the most conservative of all, rejecting only 2 of 600 true hypotheses. From these simulations, no increase in bias due to increased natural error can be demonstrated. From Table 1 it would appear that the major axes, $b_{\mathrm{P}}$ and $b_{\mathrm{S}}$, give reliable estimates of $\beta$ and the asymptotic chi-square test of $\beta=1$ performs well for censuses from $>20$ time periods. Even though collecting these many data is a formidable task for a vertebrate ecologist, many series of entomological data contain this many generations. For example, all the studies cited by Maelzer (1970) and his smallest simu- lated samples exceeded 20 generations. It was also possible that large sample size alone was not the important consideration, but rather as St. Amant (1970) and Kuno (1971) suggested, the relative error, the ratio of the $\sigma_{\epsilon}{ }^{2} / \sigma_{X}{ }^{2}$. For Eq. 5, the variance of $X(t)$ is $\sigma_{\epsilon}{ }^{2} \sum_{i=0}^{\mathrm{t}-1}\left|\beta^{i}\right|$, or, $\sigma_{\epsilon}{ }^{2}$ when $\beta=1$, so the longer the time series, the larger $\sigma_{X}^{2}$ and smaller the relative error.

Density dependence.-To test the statistical power of these analyses, simulations were also run with $\beta<1$, thus introducing negative density dependence into the simulations. One might consider the simulations as representing a population following Eq. 5 with an expected rate of increase of $r-(1-\beta) X(t)$. If $\beta \neq 1$, the equilibrium $\log$ population density, $\hat{X}$, which is asymptotically approached from above or below, is defined by

$$
\hat{X}=r /(1-\beta) \text {. }
$$

For $X(0)=20$ and $r=0$, the course of the population through time was one of stochastic exponential decrease toward an asymptotic value $\hat{X}=0$ (Table 2 ).

Again $b_{\mathrm{P}}$ and $b_{\mathrm{S}}$ appear to provide the best estimators of $\beta$. Their mean values generally approximate the true $\beta$ values more closely and are less sensitive to increased variation than are $b_{\mathrm{R}}$ or $b_{\mathrm{A}}$ and $s_{b_{\mathrm{p}}}$ or $s_{b_{\mathrm{S}}} \leqslant s_{b_{\mathrm{R}}}$ or $s_{b_{\mathrm{A}}}$ for $n>20$. Although more conservative than simple regression, major axes tests of $\beta=1$ appear to be reasonably powerful for $n>20$. For these simulations which have an appreciable period of almost exponential decrease, i.e., $X(0)>>\hat{X}$, Varley and Gradwell's (1963) suggestion was, again, too conservative especially when $\sigma_{\epsilon}{ }^{2}=1.333$. Bulmer's (1975) $b_{\mathrm{A}}$ was reasonably close to $\beta$ for large $n$, but the significance tests were quite conservative. The power of $\mathrm{R}^{*}$ is comparable to Bulmer's (1975) result for $\beta=0.90$ and $n=122$, but $\mathrm{R}$, which was supposed to be more powerful, was not.

\section{Natural errors and positive potential growth}

The parameter $r=0$ was used for comparison with the results of Maelzer (1970), Bulmer (1975) and with St. Amant's (1970) first table and one might think of all

TABLE 1. The effect of increased natural error (equation 5) on estimated slopes and number of hypotheses rejected (NHR) for 100 series of length $N$ with $r=0$ and population change independent of density

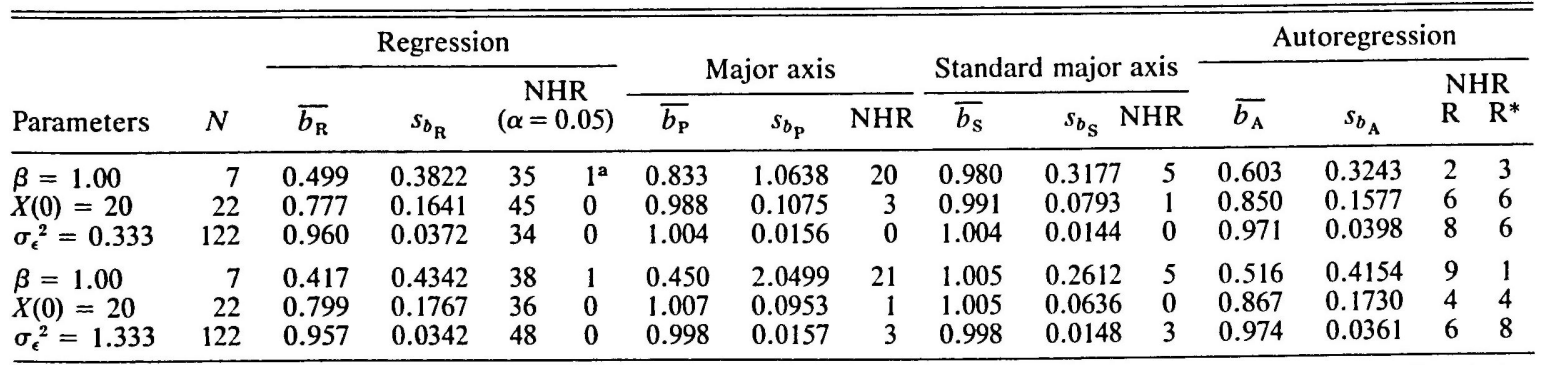

a The fourth column under regression is the number of hypotheses rejected using the test of both $b_{y \cdot x}$ and $1 / b_{x \cdot y}$ being $<1$ after Varley and Gradwell $(1963,1968)$. 
TABLE 2. Estimated slopes and number of hypotheses rejected (NHR) for 100 series of length $n$ with $r=0$ and density dependence introduced into equation 5

\begin{tabular}{|c|c|c|c|c|c|c|c|c|c|c|c|c|c|c|c|}
\hline \multirow{4}{*}{$\begin{array}{l}\text { Parameters } \\
\beta=0.96 \\
X(0)=20 \\
\sigma_{\epsilon}^{2}=0.333\end{array}$} & \multirow{4}{*}{\begin{tabular}{r}
\multicolumn{1}{c}{$N$} \\
7 \\
22 \\
122
\end{tabular}} & \multicolumn{4}{|c|}{ Regression } & \multirow{2}{*}{\multicolumn{3}{|c|}{ Major axis }} & \multirow{2}{*}{\multicolumn{3}{|c|}{ Standard major axis }} & \multicolumn{4}{|c|}{ Autoregression } \\
\hline & & \multirow[b]{2}{*}{$\overline{b_{\mathrm{R}}}$} & \multirow[b]{2}{*}{$s_{b_{\mathrm{R}}}$} & \multirow{2}{*}{\multicolumn{2}{|c|}{$\begin{array}{c}\text { NHR } \\
(\alpha=0.05)\end{array}$}} & & & & & & & \multirow[b]{2}{*}{$\overline{b_{\mathrm{A}}}$} & \multirow[b]{2}{*}{$s_{b_{\mathrm{A}}}$} & \multicolumn{2}{|c|}{ NHR } \\
\hline & & & & & & $\frac{\overline{b_{\mathrm{P}}}}{0.967}$ & $\frac{s_{b_{\mathbf{P}}}}{0.1413}$ & $\frac{\text { NHR }}{13}$ & $\frac{\overline{b_{\mathrm{s}}}}{0.970}$ & $\frac{s_{b_{\mathrm{S}}}}{0.1238}$ & $\frac{\text { NHR }}{5}$ & & & & \\
\hline & & $\begin{array}{l}0.907 \\
0.942 \\
0.959\end{array}$ & $\begin{array}{l}0.1380 \\
0.0400 \\
0.0106\end{array}$ & $\begin{array}{r}13 \\
42 \\
100\end{array}$ & $\begin{array}{l}3^{\mathrm{a}} \\
12 \\
95\end{array}$ & $\begin{array}{l}0.967 \\
0.957 \\
0.965\end{array}$ & $\begin{array}{l}0.1413 \\
0.0390 \\
0.0096\end{array}$ & $\begin{array}{l}13 \\
33 \\
99\end{array}$ & $\begin{array}{l}0.970 \\
0.958 \\
0.965\end{array}$ & $\begin{array}{l}0.1238 \\
0.0382 \\
0.0095\end{array}$ & $\begin{array}{r}5 \\
31 \\
99\end{array}$ & $\begin{array}{l}0.935 \\
1.005 \\
0.984\end{array}$ & $\begin{array}{l}0.1020 \\
0.0343 \\
0.0104\end{array}$ & $\begin{array}{l}0 \\
0 \\
0\end{array}$ & $\begin{array}{l}0 \\
0 \\
0\end{array}$ \\
\hline $\begin{array}{l}\beta=0.96 \\
X(0)=20 \\
\sigma_{\epsilon}^{2}=1.333\end{array}$ & $\begin{array}{r}7 \\
22 \\
122\end{array}$ & $\begin{array}{l}0.729 \\
0.894 \\
0.946\end{array}$ & $\begin{array}{l}0.2949 \\
0.1037 \\
0.0231\end{array}$ & $\begin{array}{l}16 \\
36 \\
97\end{array}$ & $\begin{array}{l}1 \\
4 \\
0\end{array}$ & $\begin{array}{l}0.940 \\
0.957 \\
0.968\end{array}$ & $\begin{array}{l}0.4062 \\
0.0777 \\
0.0162\end{array}$ & $\begin{array}{r}16 \\
9 \\
48\end{array}$ & $\begin{array}{l}0.970 \\
0.962 \\
0.969\end{array}$ & & $\begin{array}{r}8 \\
9 \\
46\end{array}$ & $\begin{array}{l}0.799 \\
0.965 \\
0.969\end{array}$ & & $\begin{array}{l}0 \\
0 \\
0\end{array}$ & $\begin{array}{l}1 \\
0 \\
1\end{array}$ \\
\hline $\begin{array}{l}\beta=0.90 \\
X(0)=20 \\
\sigma_{\epsilon}^{2}=0.333\end{array}$ & $\begin{array}{r}7 \\
22 \\
122\end{array}$ & $\begin{array}{l}0.891 \\
0.893 \\
0.895\end{array}$ & $\begin{array}{l}0.0704 \\
0.0242 \\
0.0126\end{array}$ & $\begin{array}{r}41 \\
100 \\
100\end{array}$ & $\begin{array}{r}25 \\
98 \\
100\end{array}$ & $\begin{array}{l}0.903 \\
0.889 \\
0.905\end{array}$ & $\begin{array}{l}0.0718 \\
0.0242 \\
0.0117\end{array}$ & $\begin{array}{r}57 \\
100 \\
100\end{array}$ & $\begin{array}{l}0.905 \\
0.899 \\
0.907\end{array}$ & $\begin{array}{l}0.0709 \\
0.0240 \\
0.0115\end{array}$ & $\begin{array}{r}37 \\
100 \\
100\end{array}$ & $\begin{array}{l}0.960 \\
0.990 \\
0.922\end{array}$ & $\begin{array}{l}0.0471 \\
0.0226 \\
0.0130\end{array}$ & $\begin{array}{l}0 \\
0 \\
0\end{array}$ & $\begin{array}{r}0 \\
0 \\
25\end{array}$ \\
\hline $\begin{array}{l}\beta=0.90 \\
X(0)=20 \\
\sigma_{\epsilon}^{2}=1.333\end{array}$ & $\begin{array}{r}7 \\
22 \\
122\end{array}$ & $\begin{array}{l}0.840 \\
0.886 \\
0.890\end{array}$ & $\begin{array}{l}0.1433 \\
0.0459 \\
0.0244 \\
\end{array}$ & $\begin{array}{r}28 \\
81 \\
100\end{array}$ & $\begin{array}{r}5 \\
42 \\
18\end{array}$ & $\begin{array}{l}0.886 \\
0.906 \\
0.924\end{array}$ & $\begin{array}{l}0.1478 \\
0.0435 \\
0.0182\end{array}$ & $\begin{array}{r}30 \\
73 \\
100\end{array}$ & $\begin{array}{l}0.894 \\
0.908 \\
0.927\end{array}$ & $\begin{array}{l}0.1369 \\
0.0421 \\
0.0169\end{array}$ & $\begin{array}{r}8 \\
69 \\
100\end{array}$ & $\begin{array}{l}0.923 \\
0.981 \\
0.916\end{array}$ & $\begin{array}{l}0.0970 \\
0.0470 \\
0.0267\end{array}$ & $\begin{array}{l}0 \\
0 \\
0\end{array}$ & $\begin{array}{r}0 \\
0 \\
43\end{array}$ \\
\hline
\end{tabular}

a The number of hypotheses rejected using the test of Varley and Gradwell $(1963,1968)$.

stochastically stable populations as having mean $r$ of zero. However if one makes the distinction between the maximum expected rate of growth with no DD constraints and the realized or effective rate of growth, $r$ might be thought of as equivalent to Andrewartha and Birch's (1954) $r_{\mathrm{m}}$ or the potential growth rate and the quantity $[r-(1-\beta) X(t)]$ as the current realized rate. In this light, simulations with $r>0$ such as in St. Amant's (1970) second table, are more realistic than this first set. Accordingly simulations with $r=1$ were run using random normal $\epsilon$ values with mean 0 and variance 0.333 .

With $r>0$ and $\beta=1$, the simulated populations grew exponentially and all four techniques gave reasonable estimates of $\beta$ (Table 3). The number of true hypotheses rejected was quite consistent with the critical level of 0.05 for runs with $n>20$ using either major axis or simple regression. Varley and Gradwell's (1963) technique resulted in only four rejections and Bulmer's (1975) none.

Simulations with $\beta<1$ and $X(0)=\hat{X}(X[0]=25$ and 10 for $\beta=0.96$ and 0.90 , Table 3) show that neither regression lines nor major axes adequately estimate $\beta$ without sustained growth or decrease phases; $\overline{b_{\mathrm{R}}}$ underestimates and $\overline{b_{\mathrm{P}}}$ and $\overline{b_{\mathrm{S}}}$ overestimate $\beta$. The statistical test of $\beta=1$ appears to be better for $b_{\mathrm{R}}$ than for $b_{\mathrm{P}}$ or $b_{\mathrm{S}}$ but one must recall Table 1 which showed $\approx 40$ true null hypotheses being rejected under other equilibrium conditions. Using regression or major axes, time series from near $\hat{X}$ can only be separated if one has prior knowledge of $r\left(r_{\mathrm{m}}\right)$ or has collected data during a phase of sustained growth or decline. Otherwise, the realized rate of increase, which is all that can be directly observed, fluctuates randomly about zero. In the first instance, if $r_{m}$ is known to be other than zero and the mean realized rate over a period of, say, 20 generations is zero, one is logically faced with the conclusion that either an unlikely series of random events has occurred or DD must be operative. The only way for DD to actually be demonstrated using these methods is to observe or experimentally induce, by density manipulation, a sustained period of increase or decrease in the population, and then these statistical methods are unnecessary for interpreting the results.

Bulmer's (1975) techniques are the only ones that seem to separate DI from DD fluctuations without pronounced increase or decrease phases. However, the power of Bulmer's (1975) R test is only $\approx 0.24$ for $n=22$ and $\beta=0.75$ and 0.68 for $n=122$ and $\beta=0.90 . R^{*}$ is more conservative, the estimated powers being 0.10 and 0.58 , respectively. With $n=122$ and $\beta=0.75$, the power appears to be $>0.99$ for both. All of these estimates are comparable to those given by Bulmer (1975). The principal disadvantage of Bulmer's (1975) tests seems to be that they are incapable of detecting DD in series of censuses which have increase or decrease phases.

Simulations with $X(0)-\hat{X}=5$ and 20 were run with $r>0$ (Table 3). These results emphasize the importance of a large enough displacement from $\hat{X}$ that the DD influence is larger than the random elements if regression or the major axes are to accurately estimate $\beta$. With $r=1.0$ and $X(0)-\hat{X}=5$, the resultant decrease phase was not pronounced enough to produce many sample slopes significantly different from one. When the displacement was increased to $20 \mathrm{log}$ units by changing $X(0)$ to 45 and 30 or to 18.5 and $10 \log$ units by changing $r$ to 0.5 , regression and both major axes gave reasonable estimates of $\beta$ (Table 3 ). The number of hypotheses rejected again increased for $n>20$. Here again Varley and Gradwell's (1963) and Bulmer's (1975) tests were too conservative.

\section{Errors of measurement}

Much of the exchange between Jolicoeur (1975) and Ricker $(1973,1975)$ concerned the use of major axes or standard major axes to estimate slopes of bivariate 
TABLE 3. Detection of density dependence with $r>0$ and $\sigma_{\epsilon}{ }^{2}=0.333$ for equilibrium $(X(0)=25,10)$ and small $(X(0)=$ $30,15)$ and large $(X(0)=45,30$ and $X(0)=30,15 ; r=0.5$ ) differences between initial and equilibrium populations

\begin{tabular}{|c|c|c|c|c|c|c|c|c|c|c|c|c|c|c|c|}
\hline \multirow{4}{*}{$\begin{array}{l}\text { Parameters } \\
\beta=1.00 \\
X(0)=20 \\
r=1.0\end{array}$} & \multirow{4}{*}{\begin{tabular}{r}
\multicolumn{1}{c}{$N$} \\
7 \\
22 \\
122
\end{tabular}} & \multicolumn{4}{|c|}{ Regression } & \multirow{2}{*}{\multicolumn{3}{|c|}{ Major axis }} & \multirow{2}{*}{\multicolumn{3}{|c|}{ Standard major axis }} & \multicolumn{4}{|c|}{ Autoregression } \\
\hline & & \multirow{3}{*}{$\begin{array}{c}\overline{b_{\mathrm{R}}} \\
0.968 \\
0.998 \\
1.000\end{array}$} & \multirow{3}{*}{$\begin{array}{c}s_{b_{\mathrm{R}}} \\
0.1151 \\
0.0210 \\
0.0015\end{array}$} & \multirow{2}{*}{\multicolumn{2}{|c|}{$\begin{array}{c}\text { NHR } \\
(\alpha=0.05)\end{array}$}} & & & & & & & \multirow{3}{*}{$\begin{array}{l}\overline{b_{\mathrm{A}}} \\
0.952 \\
1.023 \\
1.007\end{array}$} & \multirow{3}{*}{$\begin{array}{c}s_{b_{\mathrm{A}}} \\
0.0724 \\
0.0144 \\
0.0012\end{array}$} & \multirow{2}{*}{\multicolumn{2}{|c|}{$\begin{array}{l}\text { NHR } \\
\mathrm{R}\end{array}$}} \\
\hline & & & & & & \multirow{2}{*}{$\begin{array}{c}\overline{b_{\mathrm{P}}} \\
1.003 \\
1.002 \\
1.000\end{array}$} & \multirow{2}{*}{$\begin{array}{c}s_{b_{\mathrm{P}}} \\
0.1202 \\
0.0212 \\
0.0015\end{array}$} & \multirow{2}{*}{$\begin{array}{r}\text { NHR } \\
12 \\
5 \\
6\end{array}$} & \multirow{2}{*}{$\begin{array}{l}\overline{b_{\mathrm{s}}} \\
1.003 \\
1.002 \\
1.000\end{array}$} & \multirow{2}{*}{$\begin{array}{c}s_{b_{\mathrm{S}}} \\
0.1150 \\
0.0211 \\
0.0015\end{array}$} & \multirow{2}{*}{$\begin{array}{c}\text { NHR } \\
6 \\
4 \\
6\end{array}$} & & & & \\
\hline & & & & $\begin{array}{r}10 \\
6 \\
6\end{array}$ & $\begin{array}{l}3 \\
4 \\
4\end{array}$ & & & & & & & & & $\begin{array}{l}0 \\
0 \\
0\end{array}$ & $\begin{array}{l}0 \\
0 \\
0\end{array}$ \\
\hline & $\begin{array}{r}7 \\
22 \\
122\end{array}$ & & & $\begin{array}{l}21 \\
39 \\
74\end{array}$ & $\begin{array}{l}0 \\
0 \\
0\end{array}$ & & & $\begin{array}{r}17 \\
1 \\
0\end{array}$ & & & $\begin{array}{l}2 \\
0 \\
0\end{array}$ & & & $\begin{array}{r}1 \\
8 \\
22\end{array}$ & $\begin{array}{r}2 \\
8 \\
19\end{array}$ \\
\hline & $\begin{array}{r}7 \\
22 \\
122\end{array}$ & & & $\begin{array}{l}41 \\
48 \\
99\end{array}$ & $\begin{array}{l}0 \\
0 \\
0\end{array}$ & & & $\begin{array}{r}21 \\
1 \\
0\end{array}$ & & & $\begin{array}{l}1 \\
0 \\
0\end{array}$ & & & $\begin{array}{l}14 \\
14 \\
68\end{array}$ & $\begin{array}{r}1 \\
14 \\
58\end{array}$ \\
\hline & $\begin{array}{r}7 \\
22 \\
122\end{array}$ & & & $\begin{array}{l}29 \\
37 \\
85\end{array}$ & 0 & & & $\begin{array}{r}23 \\
5 \\
2\end{array}$ & & & $\begin{array}{l}5 \\
3 \\
1\end{array}$ & & & 2 & 2 \\
\hline & $\begin{array}{r}7 \\
22 \\
122\end{array}$ & & & $\begin{array}{r}29 \\
64 \\
100\end{array}$ & $\begin{array}{l}1 \\
1 \\
0\end{array}$ & & & $\begin{array}{r}16 \\
15 \\
1\end{array}$ & & & $\begin{array}{r}8 \\
10 \\
1\end{array}$ & & & $\begin{array}{r}0 \\
0 \\
19\end{array}$ & $\begin{array}{r}0 \\
1 \\
50\end{array}$ \\
\hline & $\begin{array}{r}7 \\
22 \\
122\end{array}$ & & & $\begin{array}{r}15 \\
37 \\
100\end{array}$ & $\begin{array}{r}1 \\
12 \\
96\end{array}$ & & & $\begin{array}{r}14 \\
31 \\
100\end{array}$ & & & $\begin{array}{r}10 \\
27 \\
100\end{array}$ & & & 0 & \\
\hline $\begin{array}{l}\beta=0.90 \\
X(0)=30 \\
r=1.0\end{array}$ & $\begin{array}{r}7 \\
22 \\
122\end{array}$ & & & $\begin{array}{r}39 \\
100 \\
100\end{array}$ & $\begin{array}{r}0 \\
100 \\
100\end{array}$ & & & & & & $\begin{array}{r}33 \\
100 \\
100\end{array}$ & & & $\begin{array}{l}0 \\
0 \\
0\end{array}$ & $\begin{array}{r}0 \\
0 \\
24\end{array}$ \\
\hline $\begin{array}{l}\beta=0.96 \\
X(0)=30 \\
r=0.5\end{array}$ & $\begin{array}{r}7 \\
22 \\
122\end{array}$ & & & $\begin{array}{r}8 \\
42 \\
100\end{array}$ & $\begin{array}{r}6 \\
8 \\
84\end{array}$ & & & $\begin{array}{l}13 \\
27 \\
98\end{array}$ & & & $\begin{array}{c}8 \\
23 \\
97\end{array}$ & & & & \\
\hline $\begin{array}{l}\beta=0.90 \\
X(0)=15 \\
r=0.5\end{array}$ & $\begin{array}{r}7 \\
22 \\
122\end{array}$ & & & $\begin{array}{r}21 \\
76 \\
100\end{array}$ & $\begin{array}{r}7 \\
29 \\
14\end{array}$ & & & $\begin{array}{r}24 \\
56 \\
100\end{array}$ & & & $\begin{array}{r}16 \\
51 \\
100\end{array}$ & & & $\begin{array}{l}0 \\
0 \\
0\end{array}$ & $\begin{array}{r}0 \\
0 \\
33\end{array}$ \\
\hline
\end{tabular}

relationships. My simulations (Tables 1-3) showed little difference between the two except for the much smaller standard error of $b_{\mathrm{S}}$ for equilibrium conditions when $n=7$. However, Ricker $(1973,1975)$ made a distinction between measurement error and natural variability (my Eqs. 5 and 6); whereas Jolicoeur (1975) stated that, from a statistical viewpoint, this distinction was irrelevant as long as both types of errors were distributed and sampled in the same way. The simulations discussed thus far have only involved natural variation in $r$. To test whether the distinction Ricker $(1973,1975)$ made might have any differential effect on the various statistical methods, I did a second series of simulations using Eq. 6.

Whereas the $\epsilon$ of Eq. 5 represented fluctuations in the environment, genetic or age changes in the population or other real differences, the $\gamma$ of Eq. 6 represent errors in censusing the population and are removed before calculating the estimated number in the next generation. There are some appreciable differences in the results from Eqs. 5 and 6. With $r=0$ and $\beta=1$, Eq. 6 can be rewritten as

$$
X(t+1)=X(0)+\gamma(t),
$$

so $X(t)$ does not follow a random walk beginning $X(0)$ but rather is simply a series of random numbers having mean $X(0)$ and variance $\sigma_{\gamma}{ }^{2}$. This is the model treated by Watt $(1964,1968)$ and Eberhardt (1970). Simulations using Eq. 12 produced negative $b_{\mathrm{R}}, b_{\mathrm{P}}$, and $b_{\mathrm{A}}$ values for $X(t+1)$ versus $X(t)$ (Table 4). For these data, $X(t+1)$ and $X(t)$ are statistically independent by definition. For the simulations, the mean value of $r_{1}$ was $<0.17$. Few ecologists working with comparable field data would attempt to estimate $\beta$ from bivariate plots. Only $b_{\mathrm{S}}$ is a reasonable estimator of $\beta$ for these data, but the use of the product-moment correlation coefficient to test the strength of the relationship as Ricker (1975) recommended would preclude interpreting $b_{\mathrm{S}}$. Changing $\sigma_{\gamma}{ }^{2}$ to 1.333 did not substantially affect the simulation results (Table 4$)$. With exponential increase $(\beta=1, r=1)$ or decrease $(\beta<1, r=0)$, all four estimators of $\beta$ were close to the correct value for $n \geqslant 22$, with $\overline{b_{\mathrm{P}}}$ and $\overline{b_{\mathrm{S}}}$ being slightly closer than $\overline{b_{\mathrm{R}}}$ and $\overline{b_{\mathrm{A}}}$. As with the natural errors model, $\mathrm{R}$ and $\mathrm{R}^{*}$ were very conservative tests for DD. Simulations with $\sigma_{\gamma}{ }^{2}=1.333, \beta<1, r=0$ resulted in $\overline{b_{\mathrm{P}}}$ and $\overline{b_{\mathrm{S}}}$ differing from those of Table 4 only in the third decimal place, but the standard errors were almost doubled. This reduced the number of hypotheses rejected from 100 to 1 for $\beta=0.96, n=122$ and 100 to 51 and 39 for $\beta=0.90, n=22$ for $b_{\mathrm{P}}$ and $b_{\mathrm{S}}$, respectively. The effect of increased measurement error was to increase 
TABLE 4. Estimated slopes and number of hypotheses rejected for 100 time series of length $N$ using normal random variates, $\sigma^{2}=0.333$ unless specified otherwise, to represent errors in measuring population size (Equation 6)

\begin{tabular}{|c|c|c|c|c|c|c|c|c|c|c|c|c|c|c|c|}
\hline \multirow[b]{3}{*}{ Parameter } & \multirow[b]{3}{*}{$N$} & \multicolumn{4}{|c|}{ Regression } & \multirow{2}{*}{\multicolumn{3}{|c|}{ Major axis }} & \multirow{2}{*}{\multicolumn{3}{|c|}{ Standard major axis }} & \multicolumn{4}{|c|}{ Autoregression } \\
\hline & & \multirow[b]{2}{*}{$\overline{b_{\mathrm{R}}}$} & \multirow[b]{2}{*}{$s_{b_{\mathrm{R}}}$} & \multirow{2}{*}{\multicolumn{2}{|c|}{$\begin{array}{c}\text { NHR } \\
(\alpha=0.05)\end{array}$}} & & & & & & & \multirow{3}{*}{$\begin{array}{c}\overline{b_{\mathrm{A}}} \\
-0.088 \\
-0.082 \\
-0.005\end{array}$} & \multirow{3}{*}{$\begin{array}{c}s_{b_{\mathrm{A}}} \\
0.5179 \\
0.1758 \\
0.0896\end{array}$} & \multirow{2}{*}{\multicolumn{2}{|c|}{$\begin{array}{l}\text { NHR } \\
\mathbf{R} \\
\mathbf{R}^{*}\end{array}$}} \\
\hline & & & & & & $\overline{b_{\mathrm{P}}}$ & $s_{b_{\mathbf{p}}}$ & NHR & & \multirow{2}{*}{$\begin{array}{c}s_{b_{S}} \\
0.2023 \\
0.0334 \\
0.0062\end{array}$} & \multirow{2}{*}{$\begin{array}{c}\text { NHR } \\
0 \\
0 \\
0\end{array}$} & & & & \\
\hline $\begin{array}{l}=1.00 \\
(0)=20 \\
=0.0\end{array}$ & $\begin{array}{r}7 \\
22 \\
122\end{array}$ & $\begin{array}{l}-0.161 \\
-0.111 \\
-0.013\end{array}$ & & $\begin{array}{r}73 \\
100 \\
100\end{array}$ & $\begin{array}{l}0 \\
0 \\
0\end{array}$ & & & $\begin{array}{l}29 \\
22 \\
29\end{array}$ & $\begin{array}{l}1.114 \\
1.021 \\
1.004\end{array}$ & & & & & $\begin{array}{r}69 \\
100 \\
100\end{array}$ & $\begin{array}{r}4 \\
1 \\
17\end{array}$ \\
\hline $\begin{array}{l}\text { ame as } \\
\text { ove, except }\end{array}$ & $\begin{array}{r}7 \\
22 \\
122\end{array}$ & $\begin{array}{l}-0.16 \\
-0.07 \\
-0.01\end{array}$ & & $\begin{array}{r}69 \\
100 \\
100\end{array}$ & $\begin{array}{l}0 \\
0 \\
0\end{array}$ & $\begin{array}{l}-1.8 \\
-0.2 \\
-0.0\end{array}$ & & $\begin{array}{l}31 \\
24 \\
25\end{array}$ & $\begin{array}{l}1.111 \\
1.025 \\
1.004\end{array}$ & & $\begin{array}{l}0 \\
0 \\
0\end{array}$ & $\begin{array}{l}-0.092 \\
-0.043 \\
-0.002\end{array}$ & & $\begin{array}{r}69 \\
100 \\
100\end{array}$ & $\begin{array}{r}6 \\
14 \\
27\end{array}$ \\
\hline & $\begin{array}{r}7 \\
22 \\
122\end{array}$ & & & $\begin{array}{l}0 \\
0 \\
0\end{array}$ & $\begin{array}{l}0 \\
0 \\
0\end{array}$ & & & $\begin{array}{l}1 \\
0 \\
0\end{array}$ & & & $\begin{array}{l}0 \\
0 \\
0\end{array}$ & $\begin{array}{l}0.934 \\
1.019 \\
1.007\end{array}$ & & $\begin{array}{l}0 \\
0 \\
0\end{array}$ & 0 \\
\hline $\begin{array}{l}\beta=0.9 \\
X(0)=2 \\
r=0.0\end{array}$ & $\begin{array}{r}7 \\
22 \\
122\end{array}$ & $\begin{array}{l}0.852 \\
0.934 \\
0.948\end{array}$ & & $\begin{array}{r}3 \\
4 \\
100\end{array}$ & $\begin{array}{r}0 \\
0 \\
72\end{array}$ & $\begin{array}{l}0.9 \\
0.9 \\
0.9\end{array}$ & & $\begin{array}{r}5 \\
0 \\
100\end{array}$ & & & $\begin{array}{r}2 \\
0 \\
100\end{array}$ & $\begin{array}{l}0.898 \\
0.996 \\
0.974\end{array}$ & & & 0 \\
\hline $\begin{array}{l}X(0)= \\
=0 .\end{array}$ & $\begin{array}{r}7 \\
22 \\
122\end{array}$ & & & $\begin{array}{r}16 \\
100 \\
100\end{array}$ & $\begin{array}{r}5 \\
92 \\
100\end{array}$ & & & $\begin{array}{r}26 \\
100 \\
100\end{array}$ & & & & & & $\begin{array}{l}0 \\
0 \\
0\end{array}$ & 3 \\
\hline $\begin{array}{l}\beta=0.96 \\
X(0)=25 \\
r=1.0\end{array}$ & $\begin{array}{r}7 \\
22 \\
122\end{array}$ & $\begin{array}{l}-0.159 \\
-0.033 \\
-0.009\end{array}$ & $\begin{array}{l}0.3414 \\
0.2288 \\
0.0934\end{array}$ & $\begin{array}{r}72 \\
100 \\
100\end{array}$ & $\begin{array}{l}0 \\
0 \\
0\end{array}$ & $\begin{array}{r}-1.150 \\
0.100 \\
0.679\end{array}$ & $\begin{array}{r}8.0338 \\
3.5755 \\
10.6093\end{array}$ & $\begin{array}{l}23 \\
22 \\
25\end{array}$ & $\begin{array}{l}1.094 \\
1.031 \\
1.004\end{array}$ & & $\begin{array}{l}0 \\
0 \\
0\end{array}$ & $\begin{array}{r}-0.069 \\
0.007 \\
-0.001\end{array}$ & & $\begin{array}{r}69 \\
100 \\
100\end{array}$ & $\begin{array}{r}1 \\
15 \\
20\end{array}$ \\
\hline $\begin{array}{l}\beta=0.90 \\
X(0)=10 \\
r=1.0\end{array}$ & $\begin{array}{r}7 \\
22 \\
122\end{array}$ & $\begin{array}{l}-0.174 \\
-0.081 \\
-0.012\end{array}$ & & $\begin{array}{r}75 \\
100 \\
100\end{array}$ & $\begin{array}{l}0 \\
0 \\
0\end{array}$ & $\begin{array}{l}-1.789 \\
-1.185 \\
-0.289\end{array}$ & 12.8334 & $\begin{array}{l}40 \\
27 \\
19\end{array}$ & & & $\begin{array}{l}0 \\
0 \\
0\end{array}$ & $\begin{array}{l}-0.102 \\
-0.048 \\
-0.004\end{array}$ & & $\begin{array}{r}72 \\
100 \\
100\end{array}$ & $\begin{array}{r}4 \\
6 \\
25\end{array}$ \\
\hline $\begin{array}{l}\beta=0.75 \\
X(0)=4 \\
r=1.0\end{array}$ & $\begin{array}{r}7 \\
22 \\
122\end{array}$ & $\begin{array}{l}-0.152 \\
-0.015 \\
-0.014\end{array}$ & $\begin{array}{l}0.2938 \\
0.2295 \\
0.0940\end{array}$ & $\begin{array}{r}72 \\
100 \\
100\end{array}$ & $\begin{array}{l}0 \\
0 \\
0\end{array}$ & $\begin{array}{l}-0.343 \\
-0.111 \\
-0.127\end{array}$ & & $\begin{array}{l}24 \\
24 \\
22\end{array}$ & $\begin{array}{l}1.076 \\
1.027 \\
1.004\end{array}$ & & $\begin{array}{l}0 \\
0 \\
0\end{array}$ & $\begin{array}{r}-0.072 \\
0.026 \\
-0.007\end{array}$ & $\begin{array}{l}0.3938 \\
0.2590 \\
0.0963\end{array}$ & $\begin{array}{r}69 \\
99 \\
100\end{array}$ & $\begin{array}{r}1 \\
5 \\
17\end{array}$ \\
\hline
\end{tabular}

the negative bias of $b_{\mathrm{R}}$, to decrease the autocorrelation enough to cause $b_{\mathrm{A}}$ to underestimate $\beta$, and to increase the standard errors of both estimators. The number of hypotheses rejected using regression and autoregression were not changed appreciably, whereas Varley and Gradwell's $(1963,1968)$ test did not reject any of these false hypotheses.

The results of simulations with $\beta<1, r=1$, and $X(0)=\hat{X}$, were indistinguishable from those with $\beta=1, r=0$, even with $\beta=0.75$, except that $s_{b_{\mathrm{P}}}$ values were as much as $4 \times$ larger and $\overline{b_{\mathrm{P}}}$ varied widely (Table 4). Simulations with $\beta<1, r=1.0$, and $X(0)>\hat{X}$ produced results (not included) generally comparable to those from Eq. 5 shown in Table 3 . Standard errors of slope estimates were reduced by at least one third, and $\overline{b_{\mathrm{R}}}$ was slightly more negatively biased with measurement as opposed to natural error.

\section{Both measurement and natural error}

Because of the differences between the results from Eqs. 5 and 6, especially in the case of random fluctuations around $\hat{X}$, a third complete set of simulations was run using Eq. 7 with $\epsilon$ and $\gamma$ being drawn from the same distribution. The variances of $\epsilon$ and $\gamma$ were set at one half their previous value so total error variance would be unchanged. These are perhaps the most realistic simulations because real data will contain stochastic elements from both environmental fluctuation and census errors.
The results from Eq. 7 are intermediate between those of Eqs. 5 and 6 (Table 5). For random fluctuations around $\hat{X}$ (the first three sets of Table 5), none of the estimators of slope are accurate. Hypothesis tests using regression, $\mathrm{R}$, and $\mathrm{R}^{*}$ show some tendency toward increased rejection rates as $\beta$ decreases but of these, only $\mathrm{R}^{*}$ has an acceptable probability of type I error. With $\beta=0.75$ and $X(0)=4$, the number of hypotheses rejected using $R^{*}$ were 4,12 , and 76 for $n=7,22$, and 122 , respectively. With initial values much greater than equilibrium, $b_{\mathrm{P}}$ and $b_{\mathrm{S}}$ were the most accurate and precise estimators of $\beta$; once again the $\mathrm{R}$ and $\mathrm{R}^{*}$ tests were too conservative.

The values of $r, X(0)$, and $\sigma^{2}$ used in these simulations may be unrealistic, however almost identical results were obtained using $r$ and $\sigma$ values one tenth those given, with correspondingly reduced $X(0)$ values. Hence, the important consideration appears to be the magnitude of the deterministic elements, $r$ and $|X(0)-\hat{X}|$, in relation to the random elements, $\epsilon$ and $\gamma$, rather than the absolute magnitude of any of these values.

Statistical tests for departures of estimated slopes from 1 rely on the assumption of normality of error terms. As a final comparison of the various analyses. the entire set of simulations was rerun using uniformly distributed random numbers with mean and variance equal to those of $\epsilon$ and $\gamma$; results were comparable to those already discussed for every simulation. There- 
TABLE 5. Estimated slopes and hypotheses rejected from simulations using equation 7 . For all runs $\sigma_{\epsilon}^{2}=\sigma_{\gamma}^{2}=0.167$.

\begin{tabular}{|c|c|c|c|c|c|c|c|c|c|c|c|c|c|c|c|}
\hline \multirow[b]{3}{*}{ Parameters } & \multirow[b]{3}{*}{$N$} & \multicolumn{4}{|c|}{ Regression } & \multirow{2}{*}{\multicolumn{3}{|c|}{ Major axis }} & \multirow{2}{*}{\multicolumn{3}{|c|}{ Standard major axis }} & \multicolumn{4}{|c|}{ Autoregression } \\
\hline & & \multirow[b]{2}{*}{$\overline{b_{\mathrm{R}}}$} & \multirow[b]{2}{*}{$s_{b_{\mathrm{R}}}$} & \multirow{2}{*}{\multicolumn{2}{|c|}{$\begin{array}{c}\text { NHR } \\
(\alpha=0.5)\end{array}$}} & & & & & & & \multirow[b]{2}{*}{$\overline{b_{\mathrm{A}}}$} & \multirow[b]{2}{*}{$s_{b_{\mathrm{A}}}$} & \multicolumn{2}{|c|}{ NHR } \\
\hline & & & & & & $\frac{\overline{b_{\mathrm{P}}}}{0.460}$ & $\frac{s_{b_{\mathrm{P}}}}{3.5379}$ & $\frac{\mathrm{NHR}}{25}$ & $\frac{\overline{b_{s}}}{1.068}$ & $\begin{array}{c}\frac{s_{b_{\mathrm{S}}}}{} \\
0.2552\end{array}$ & $\begin{array}{r}\overline{\mathrm{NHR}} \\
0\end{array}$ & & & $\mathrm{R}$ & $\mathrm{R}^{*}$ \\
\hline $\begin{array}{l}\beta=1.00 \\
X(0)=20 \\
r=0.0\end{array}$ & $\begin{array}{r}7 \\
22 \\
122\end{array}$ & $\begin{array}{l}0.220 \\
0.563 \\
0.897\end{array}$ & $\begin{array}{l}0.4293 \\
0.2572 \\
0.0721\end{array}$ & $\begin{array}{l}41 \\
74 \\
71\end{array}$ & $\begin{array}{l}0 \\
0 \\
0\end{array}$ & $\begin{array}{l}0.460 \\
0.930 \\
1.003\end{array}$ & $\begin{array}{l}3.5379 \\
0.7455 \\
0.0159\end{array}$ & $\begin{array}{r}25 \\
4 \\
0\end{array}$ & $\begin{array}{l}1.068 \\
1.017 \\
1.003\end{array}$ & $\begin{array}{l}0.2552 \\
0.0764 \\
0.0139\end{array}$ & $\begin{array}{l}0 \\
0 \\
0\end{array}$ & $\begin{array}{l}0.354 \\
0.629 \\
0.909\end{array}$ & $\begin{array}{l}0.4802 \\
0.2540 \\
0.0701\end{array}$ & $\begin{array}{l}23 \\
37 \\
40\end{array}$ & $\begin{array}{l}2 \\
2 \\
2\end{array}$ \\
\hline $\begin{array}{l}\beta=0.96 \\
X(0)=25 \\
r=1.0\end{array}$ & $\begin{array}{r}7 \\
22 \\
122\end{array}$ & $\begin{array}{l}0.197 \\
0.480 \\
0.793\end{array}$ & $\begin{array}{l}0.4210 \\
0.2671 \\
0.0957\end{array}$ & $\begin{array}{r}43 \\
85 \\
100\end{array}$ & $\begin{array}{l}0 \\
0 \\
0\end{array}$ & $\begin{array}{l}4.470 \\
0.904 \\
1.005\end{array}$ & $\begin{array}{r}31.0507 \\
1.0959 \\
0.0092\end{array}$ & $\begin{array}{r}26 \\
7 \\
0\end{array}$ & $\begin{array}{l}1.084 \\
1.005 \\
1.004\end{array}$ & $\begin{array}{l}0.2866 \\
0.0677 \\
0.0069\end{array}$ & $\begin{array}{l}1 \\
0 \\
0\end{array}$ & $\begin{array}{l}0.321 \\
0.553 \\
0.814\end{array}$ & $\begin{array}{l}0.4167 \\
0.2794 \\
0.0980\end{array}$ & $\begin{array}{l}19 \\
42 \\
91\end{array}$ & $\begin{array}{r}3 \\
8 \\
17\end{array}$ \\
\hline $\begin{array}{l}\beta=0.90 \\
X(0)=10 \\
r=1.0\end{array}$ & $\begin{array}{r}7 \\
22 \\
122\end{array}$ & $\begin{array}{l}0.082 \\
0.450 \\
0.696\end{array}$ & $\begin{array}{l}0.4195 \\
0.2428 \\
0.0980\end{array}$ & $\begin{array}{r}55 \\
90 \\
100\end{array}$ & $\begin{array}{l}0 \\
0 \\
0\end{array}$ & $\begin{array}{l}1.433 \\
0.933 \\
1.006\end{array}$ & $\begin{array}{r}10.6635 \\
0.4884 \\
0.0095\end{array}$ & $\begin{array}{r}25 \\
3 \\
n\end{array}$ & $\begin{array}{l}1.042 \\
1.014 \\
1.004\end{array}$ & $\begin{array}{l}0.1929 \\
0.0457 \\
0.0064\end{array}$ & $\begin{array}{l}1 \\
0 \\
0\end{array}$ & $\begin{array}{l}0.204 \\
0.529 \\
0.716\end{array}$ & $\begin{array}{l}0.4687 \\
0.2599 \\
0.0999\end{array}$ & $\begin{array}{r}33 \\
54 \\
100\end{array}$ & $\begin{array}{r}2 \\
7 \\
32\end{array}$ \\
\hline $\begin{array}{l}\beta=0.96 \\
X(0)=45 \\
r=1.0\end{array}$ & $\begin{array}{r}7 \\
22 \\
122\end{array}$ & $\begin{array}{l}0.866 \\
0.938 \\
0.951\end{array}$ & $\begin{array}{l}0.1717 \\
0.0333 \\
0.0082\end{array}$ & $\begin{array}{r}8 \\
30 \\
100\end{array}$ & $\begin{array}{r}1 \\
7 \\
88\end{array}$ & $\begin{array}{l}0.958 \\
0.957 \\
0.961\end{array}$ & $\begin{array}{l}0.1656 \\
0.0309 \\
0.0068\end{array}$ & $\begin{array}{r}7 \\
21 \\
100\end{array}$ & $\begin{array}{l}0.965 \\
0.958 \\
0.961\end{array}$ & $\begin{array}{l}0.1454 \\
0.0301 \\
0.0067\end{array}$ & $\begin{array}{r}3 \\
19 \\
100\end{array}$ & $\begin{array}{l}0.901 \\
1.004 \\
0.977\end{array}$ & $\begin{array}{l}0.1473 \\
0.0264 \\
0.0087\end{array}$ & $\begin{array}{l}0 \\
0 \\
0\end{array}$ & $\begin{array}{l}0 \\
0\end{array}$ \\
\hline
\end{tabular}

fore, my general results do not seem to depend on the particular distribution of error terms.

\section{CONCLUSIONS}

Major axes performed much better than regression in the specific case $(r=0.0, \beta=1.0)$ explored by Maelzer (1970) and St. Amant (1970), but none of the techniques tested can detect DD in a series of data varying randomly around some equilibrium value with large measurement errors. The equilibrium population density with $r=0.0$ and $\beta=1.0$ might be called a neutral equilibrium (as in May's [1973] neutral stability) in that it is simply the initial value of the population and any perturbation will result in a new "equilibrium" whereas the equilibria obtained with $r>0$ and $\beta<1$ are stable equilibria within the limits of stochastic variation. However, as stated previously, these models can be identified only by observing population trends far enough from the equilibrium to allow deterministic growth or decrease to dominate the random elements. At equilibrium, $b_{\mathrm{R}}$ underestimates $\beta$ while $b_{\mathrm{P}}$ and $b_{\mathrm{S}}$ are approximately equal to 1.0 regardless of $\beta$. Interestingly, it is under such conditions that $b_{\mathrm{R}}$ provides its poorest estimate of $\beta$. If the absolute value of $X(0)-\hat{X}$ is large enough to permit estimation of $\beta$ by any of the error regression techniques, then $b_{\mathrm{R}}$, while still an underestimate of $\beta$ for the reasons discussed by the critics cited in the introduction, is not much worse than is $b_{\mathrm{P}}$ or $b_{\mathrm{S}}$. Nevertheless, the major axes provide more reliable estimates of $\beta$ and more conservative tests of DD and respond less to increased random variation than does regression.

Which major axis, ordinary or standard, to use is more difficult to determine on the basis of the simulation results. The slope of the standard major axis is generally less variable and the hypothesis test more conservative for small sample sizes. However, I am more comfortable with the statistical arguments favoring the use of the major axis; it is both a least squares (Deming 1943) and maximum likelihood estimator
(Moran 1971) of the true relationship, given equal error in both variables. In addition, Ricker's (1973, 1975) objections to the major axis in general can be met for this particular problem; both measurement units and error ratio are determined by the definition of the problem. Varley and Gradwell's (1968) technique is too conservative in that it ignores the ratio of error variances.

The same general conclusions apply to the natural variation model, except that the autoregression analysis of Bulmer (1975) does provide a good estimate of $\beta$, allowing discrimination of populations following a random walk from those fluctuating randomly about an equilibrium value. Although it is the most recently proposed DD statistic, Bulmer's (1975) $b_{\mathrm{A}}$ is biased by measurement error; the $\mathrm{R}$ and $\mathrm{R}^{*}$ tests do not detect DD when population trends are evident enough to make regression or major axes reliable; and the analysis can be applied only to autoregressive processes with low measurement error and not to more general cases of fitting lines to points with error in both variables. The dilemma facing the investigator is that, if purely statistical means of detecting DD are to be used, the most reliable analysis depends on the underlying model and parameters one is trying to estimate.

Though this paper has focused on the particular problem of detecting DD from a series of censuses, I believe the discussion of regression versus major axes also applies to many other situations. The assumption of equality of parametric error variances $(\lambda=1)$ may well be met by censuses of the numbers alive at the start and end of a single generation or stage therein. If so, the major axes would also be the best estimators of mortality slopes determined across generations subject to the constraints already mentioned. Certainly anytime $\lambda$ can be reasonably estimated, the formula of Deming (1943) will give more reliable results than simple linear regression. If $\lambda$ can not be estimated, then Varley and Gradwell's (1963) suggestion could be followed though it will always be conservative. The stan- 
dard major axis (Ricker 1973, 1975) was more reliable than the ordinary major axis for small samples and did not require information about $\lambda$, and might prove a less conservative alternative, but further empirical testing is necessary in light of Jolicoeur's (1975) comments.

\section{ACKNOWLEDGMENTS}

This study was supported by University of Kansas General Research Grants 3093-5038 and 3244-X038. Many of the ideas arose during my tenure as visiting scientist at the Unit for Research on Behavioral Systems, Laboratory of Brain Evolution and Behavior, National Institute of Mental Health. My thanks to James Mosimann, John Bartko, John Calhoun, Paul MacLean and Cecelia Clark of NIH and NIMH for their assistance; to Jim Koeppl, Mark Boyce and W. D. Klimstra for comments on earlier drafts of this manuscript; and particularly to the anonymous reviewers whose suggestions greatly strengthened this study.

\section{Literature Cited}

Andrewartha, H. G., and L. C. Birch. 1954. The distribution and abundance of animals. Univ. of Chicago Press, Chicago. 782 p.

Benson, J. F. 1973. Some problems of testing for densitydependence in animal populations. Oecologia 13:183-190.

Bulmer, M. G. 1975. The statistical analysis of density dependence. Biometrics 31:901-911.

Deming, W. E. 1943. Statistical adjustment of data. John Wiley, New York. 261 p.

Dempster, J. P. 1975. Animal population ecology. Academic Press, New York. 155 p.

Eberhardt, L. L. 1970. Correlation, regression, and density dependence. Ecology 51:306-310.

Hassell, M. P. 1975. Density-dependence in single-species populations. J. Anim. Ecol. 44:283-295.

Itô, Y. 1972. On the methods for determining densitydependence by means of regression. Oecologia 10:347-372.

Jolicoeur, P. 1975. Linear regressions in fishery research: some comments. J. Fish. Res. Board Canada 32:14911494.

Jolicoeur, P., and A. A. Heusner. 1971. The allometry equation in the analysis of the standard oxygen consumption and body weight of the white rat. Biometrics 27:841-855.

Jolicoeur, P., and J. E. Mosimann. 1968. Intervalles de confiance pout la pente de l'axe majeur d'une distribution normale bidimensionnelle. Biom. Praxim. 9:121-140.

Kuno, E. 1971. Sampling error as a misleading artifact in "key factor analysis." Res. Popul. Ecol. 13:28-45.

Luck, R. F. 1971. An appraisal of two methods of analyzing insect life tables. Canadian Entomol. 103:1261-1271.
MacArthur, R. H., and E. O. Wilson. 1967. The theory of island biogeography. Princeton Univ. Press, Princeton. New Jersey. 203 p.

Maeizer, D. A. 1970. The regression of $\log N_{n+1}$ on $\log N_{n}$ as a test of density dependence: an exercise with computer-constructed density-independent populations. Ecology 51:810-822.

May, R. M. 1973. Stability and complexity in model ecosystems. Princeton Univ. Press, Princeton, New Jersey. 235 p.

May, R. M., G. R. Conway, M. P. Hassell, and T. R. E. Southwood. 1974. Time delays, density-dependence and single-species oscillations. J. Anim. Ecol. 43:747-770.

Moran, P. A. P. 1971. Estimating structural and functional relationships. J. Multivar. Anal. 1:232-255.

Morris, R. F. 1959. Single-factor analysis in population dynamics. Ecology 40:580-588.

Pearson, K. 1901. On lines and planes of closest fit to systems of points in space. Philos. Mag., Ser. 6, 2:559-572.

Pianka, E. R. 1970. On $r$ - and $K$-selection. Am. Nat. 104:592-597.

- 1972. $r$ and $K$ selection or $b$ and $d$ selection. Am. Nat. 106:581-588.

Pielou, E. C. 1974. Population and community ecology. Gordon and Breach, London. $424 \mathrm{p}$.

Ricker, W. E. 1973. Linear regressions in fishery research. J. Fish. Res. Board Canada 30:409-434.

1975. A note concerning Professor Jolicoeur's comments. J. Fish. Res. Board Canada 32:1494-1498.

Slade, N. A. 1976. Statistical detection of densitydependence in a series of sequential censuses. Bull. Ecol. Soc. Am. 57:35.

Sokal, R. R., and F. J. Rohlf. 1969. Biometry. W. H. Freeman, San Francisco. $776 \mathrm{p}$.

St. Amant, J. L. S. 1970. The detection of regulation in animal populations. Ecology 51:823-828.

Teissier, G. 1948. La relation d'allométrie: sa signification statistique et biologique. Biometrics 4:14-18.

Varley, G. C., and G. R. Gradwell. 1963. Predatory insects as density dependent mortality factors. Proc. XVI Int. Cong. Zool., Washington, D.C. 1:240.

132. 1968. Population models for the winter month, $p$. 132-142. In T. R. E. Southwood [ed.] Insect abundance. Symp. R. Entomol. Soc. London No. 4.

Varley, G. C., G. R. Gradwell, and M. P. Hassell. 1974. Insect population ecology. Univ. California Press, Berkeley. $212 \mathrm{p}$.

Wallace, B. 1975. Hard and soft selection revisited. Evolution 29:465-473.

Watt, K. E. F. 1964. Density-dependence in population fluctuations. Canadian Entomol. 96:1147-1148.

1968. Ecology and resource management. McGraw-Hill, New York. 450 p. 